\title{
Collective Spatial Strategies in Urban Kampung Communal Toilet
}

\author{
Yandi Andri Yatmo, Paramita Atmodiwirjo \\ Department of Architecture, \\ Universitas Indonesia, Indonesia \\ yandiay@yahoo.co.uk
}

\begin{abstract}
Living in a high density urban kampung with limited space and resources involves challenges to meet basic service needs. Various collective spatial systems represent the community strategies in dealing with their limited situation. This paper addresses the communal toilet system in urban kampung as a collective spatial system developed by the community. The study identifies various spatial strategies incorporated within the system, as well as social structures embedded within the spatial practice. The understanding of spatial and social system in the communal toilet system provides some insights for the development of appropriate spatial strategies for urban kampung communities.
\end{abstract}

Keywords: urban kampung, community, spatial, strategies, toilet

eISSN 2514-751X @ 2018. The Authors. Published for AMER ABRA cE-Bs by e-International Publishing House, Ltd., UK. This is an open-access article under the CC BY-NC-ND license (http://creativecommons.org/licenses/bync-nd/4.0/). Peer-review under responsibility of AMER (Association of Malaysian Environment-Behaviour Researchers), ABRA (Association of Behavioural Researchers on Asians) and $c E-B s$ (Centre for EnvironmentBehaviour Studies), Faculty of Architecture, Planning \& Surveying, Universiti Teknologi MARA, Malaysia.

DOI: https://doi.org/10.21834/aje-bs.v3i6.236 


\subsection{Introduction}

Human living environment represents an inter-play between physical entities and social structure. Acomprehensive inquiry into human spatial environment requires an understanding on the role of society in the production of space (Lefebvre, 1991; Borden et al., 2001). A new dimension of seeing and understanding our urban environment is needed in order to comprehend various spatial strategies that emerge within the process of spatiality. It becomes important to uncover the everyday spatial practice for better comprehension of architectural space within its social contexts. "... an acknowledgement of the everyday, with its engaged actions and occupations, inevitably leads to recognition of the political and social content of architectural production" (Wigglesworth and Till, 1998: 9).

This is particularly relevant when discussing urban spatial process within the context of third world cities, with various layers of issues related to poverty, inadequate spaces and limited resources. This paper addresses the need to discover the spatial strategies that incorporate the social dimension of living space, as practiced by urban kampung communities. Urban kampung represents a spatial process involving space, human needs and social relations, which becomes meaningful territory for residents as settings of services and social relations (Schnell and Goldhaber, 2001). Urban kampung is a living space for a large proportion of underprivileged population in many third world countries, who have continuously faced the challenge to meet the demand of adequate space and basic services.

Collective strategies often become a logical consequence in responding to the limited space and resources. One of the strategies practiced by urban kampung communities is the communal use of the sanitation facilities. Lack of access to proper sanitation facilities is experienced by around $39 \%$ of the global population, $72 \%$ of which is in Asia (WHO and UNICEF, 2010). Very often shared sanitation facilities becometheonly possible solution forlow income communities, especially in urban areas with insufficient settlement space (WegelinSchuringa and Kodo, 1997; WHO and UNICEF, 2010). Nevertheless, it is not merely a technical solution to the sanitation problems, but also representing various social dimension of the community everyday life. This study explores the spatial strategies embedded in the communal toilet as practiced by an urban kampung community in a poor neighbourhood in Jakarta.

\section{Understanding collective spatial strategies}

Space should not be seen merely as formal material entities; embedded within the space is the spatial practice of the people occupying the space - as the subjectsin the space. The use of the term 'subjects' rather than 'users' or 'inhabitants' (Borden et al., 2001) emphasises on the important role of the social actors in the production of the space (Lefebvre, 1991). Space is considered as a resultant of activities practiced by the subjects, which actively produce the space. The importance of spatial practice is also outlined in the comprehension of neighbourhood as the "locations where human activity is centered upon social reproduction; or daily householdactivities, socialinteraction, andengagementwith politicaland economic structures" (Martin, 2003: 365).

Active spatial practice by the subjects also represents their capabilities in producing, appropriating and transforming the space they live within. There are "the 'potential energies' 
of groups act to transform and create new social spaces" (Borden et al., 2001: 17), suggesting that the space is produced and reproduced by the collective actions of the subjects. Collective action often becomes a community's way to generate solution to the problems in their living space, as demonstrated by various examples (Oldfield, 2000; Ahmed and Sohail, 2003; Inerfeld and Blom, 2002). The emergence of collective strategies is particularly prominent among the communities with some disadvantages - in terms of economics, spaces and access to services. It becomes necessary to uncover the collective spatial practice as a way to understand the exchange among space, inhabitants, their needs and collective potentials.

In understanding how the collective strategies may contribute to the production of spatiality in particular communities, there is a need to discover the details of everyday practice, which often seems familiar and ordinary. Understanding everyday spatial practice is an understanding of the possibilities and the potential appropriation of spaces. Everyday spatial practice contains complex living patterns and relations behind the routine and ordinary activities. "Yet these, and other spaces of the familiar are there to be claimed and transformed into settings of extraordinary potential" (Wigglesworth and Till, 1998: 9). Everyday practice might be "too visible, right in front of our eyes, buried in the underlying infrastructure of everyday lives..." (Pile, 2001:264) and this becoming overlooked and unknown. To uncover the practice, it becomes necessary to dig beneath the surface (Borden et al., 2001). This study is an attempt for a closer look into the collective spatial system that emerged within the urban kampung community in the forms of communal toilet, through an inquiry into its everyday spatial practice.

\subsection{Methodology}

The study was conducted in an urban kampung neighbourhood unit in Semper Barat, North Jakarta, Indonesia. The area is one of the 'poverty pockets' in Jakarta, representing the living spaces of the underprivileged groups. The study area is primarily characterised by small dwelling units, the majority are rented, single- room dwelling units, lining up along the narrow alleys. The housing condition is generally far from satisfactory, with limited dwelling space, poor quality living environment and lack of access to water and sanitary facilities

The study was an exploratory study, using qualitative methods as a way to identify and explore the existing system as occurred in everyday life of the community. In particular the study was a detailed inquiry into the community toilet, to identify the spatial system embodied in it and the spatial practice that is produced by the actors and activities as the everyday users of the communal toilet. The study was conducted through close and detailed observation to reveal the everyday spatial patterns and activity patterns associated with the communal toilet. The method is developed based on the understanding that in the closer study into the details of the spatial practice, it is necessary to "be explicit about what particular activity or activities are being undertaken: what are the energies deployed, what patterns they create, what objects do they produce..." (Borden et al., 2001: 18). In addition, a study of community and its spatiality requires an understanding of social action and social structure which construct the community space, including the actors involved and their agendas (Martin, 2003). 
The study of the communal toilet include the detailed observation of physical spaces and activities of the communal toilet system, complemented by in-depth interviews with the residents to reveal social and behavioural dimensions related to the communal toilet system. The study of the space included the space of the toilet units, the physical amenities and the surrounding neighbourhood as the living space of the residents. The study of the activities included the users, the patterns of uses and activities, and the relationship between the users and the space. The findings on the communal toilet system were then compiled and represented through the mapping of the toilet as spatial elements and the mapping of the everyday utilisation patterns. These data become the basis in concluding the spatial system as represented by the relationship between the actors, the physical space, and the collective actions underlying the spatial strategies of the community.

\subsection{Results and Discussion}

\subsection{The role of communal toilet in urban kampong neighbourhood}

The communal toilet provides important access to sanitary services for the residents in the study area. The majority of the dwellings - especially the rental units - have very limited living space, usually only one room for all daily living activities. The owners of the rental dwelling units do not normally provide bathroom or toilet for each unit. The needs for sanitary facilities are met by shared bathroom/ toilet built for certain groups of rental dwelling units (usually one bathroom/toilet provided for 3-5 units) or by the public communal toilet consisting of a number of cubicles used by many residents around the area.

The communal toilet was built by a male resident who owns a number of rental dwelling units in the area. The owner initially built the toilet to cater for the

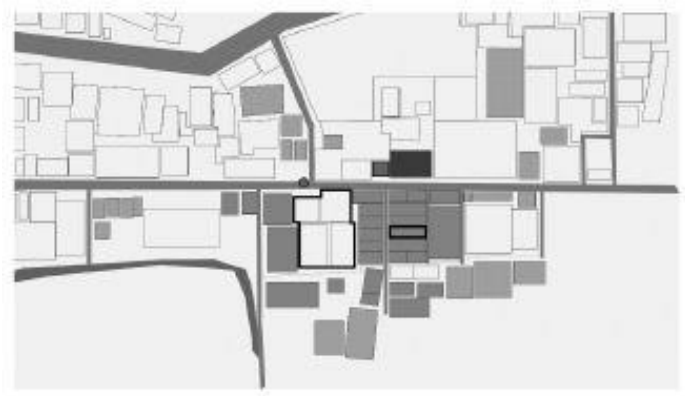

$\square$ owner of community toilet toilet attendance/maintenance dwelling units owned by community toilet owner

dwelling units not owned by community toilet owner but also served by communal toilet

Figure 1: Communal toilet provides services for many dwelling units

\subsection{The physical space and service provision of communal toilet}

The physical space of the communal toilet consists of six toilet cubicles: three large cubicles for bathing and urinating/excreting, two small cubicles for urinating/excreting only, and one small cubicle for bathing only. Three other small cubicles are used as storage spaces. Each toilet cubicle - both large and small consists of a squatting toilet on an elevated platform, 
with a door to provide privacy for the users. The floors are finished with ceramic tiles. The cubicles are in a linear arrangement, facing an open space where people can stand in front of the door, queuing to use the toilet. In general the physical condition of the toilet is not very good, with some worn out and broken elements. Nevertheless it is the only communal toilet found in the neighbourhood, so it becomes the only choice for many residents with no provision of private toilets.

The toilet cubicles are not equipped with water but there are two water sources located nearby. The first source is a water storage pond located next to the toilet cubicles, storing the clean water from city piped water system. This water source belongs to the owner of the communal toilet and the residents could collect the water by paying an amount of money (Rp 500 per bucket or paid weekly). The second source is a well located around 15 metres from the communal toilet, from which the residents could collect the water for free. These two water sources become the important source of water for the residents, since the majority of the dwellings do not have access to clean water.

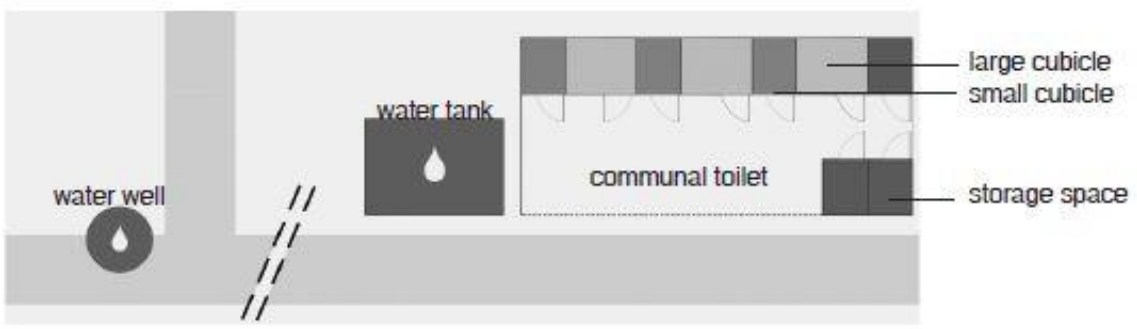

Figure 2: Layout of the communal toilet and water sources

\subsection{Collective patterns of use in communal toilet}

The communal toilet becomes a setting for various activities of the residents, including bathing, teeth cleaning, urinating, excreting and washing clothes. The existence of water sources makes the communal toilet becomes an important hub for obtaining water for daily use, both for use in the toilet and to bring to individual dwelling units for other domestics uses. Figure 3 illustrates various activity flows associated with communal toilet, showing the relationship between the communal toilet, water source and the residents.

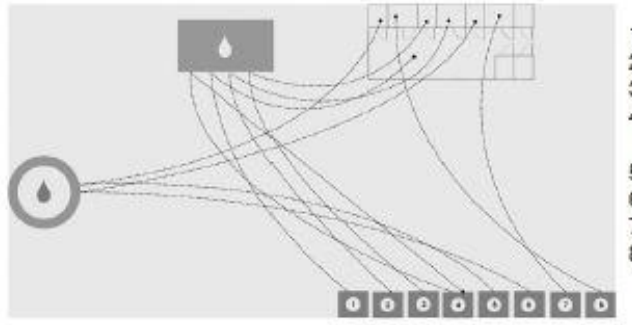

1. collect water from water tank, use for washing

2. collect water from water tank, use for bathing

3. collect water from water tank, use for excreting

4. collect water from water tank, bring home for other uses

5. collect water from well, use for washing

6. collect water from well, use for excreting

7. bring water supply from home, use for bathing

8. bring water supply from home, use for excreting

Figure 3: Various activity flows in communal toilet 
Our observation suggests that approximate daily user of the communal toilet may reach 250 . With only six toilet cubicles, there is definitely a need for regulating the use of the toilet in order to avoid long queues. During the observation, we found that the community has developed an informal agreement on the pattern of use of the communal toilet which organises the use of the toilet by different section of communities at different times of the day. The communal toilet is open for use during the day, however, the opportunities for collecting clean water from the storage tank is limited to certain time period (from 06.00 to 11.00 in the morning and from 14.00 to 18.00 in the afternoon). These are the period of time when people normally take a bath and do domestic chores of washing.
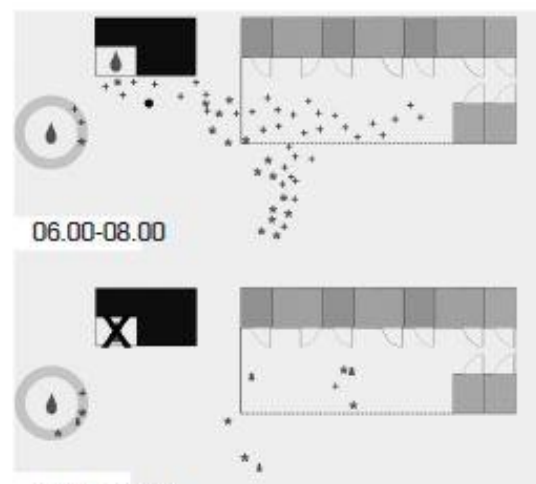

$11.00-14.00$

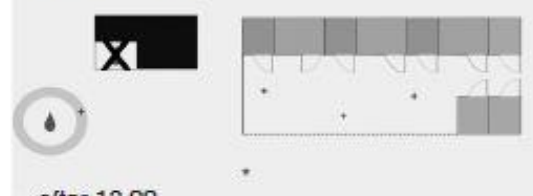

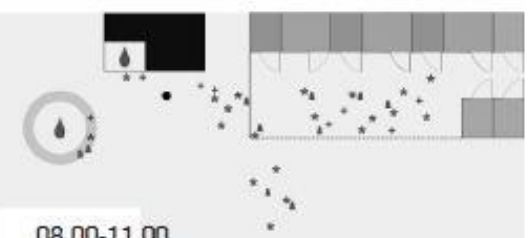

08.00-11.00

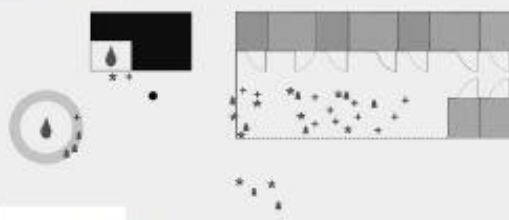

$14.00-18.00$

+ males and school children

* females

a young children

- toilet attendance/maintenance

- water sources

Figure 4: Patterns of communal toilet uses at different time of the day

The use of the communal toilet during early morning period (06.00-08.00) is primarily dominated by children, teenagers and male adults who take their morning bath before they go to school or work. Some female adults were also observed around the communal toilet for collecting clean water they need for various domestic uses and for water supply kept in their dwelling units. The total number of the users may reach 250; with the total number of clean water buckets collected around 300 . The use of the communal toilet in later morning period (08.00-11.00) is dominated by the female adults and younger children who are not in school yet. The main activities include washing clothes and bathing the young children, which are done in the space in front of the toilet cubicles. The total number of the users is around 60 people with around 140 clean water bucket collection.

In the mid afternoon (11.00-14.00) there are fewer people and activities observed around the communal toilet. The piped water storage is closed during this period and the 
activities are primarily urinating or excreting, with the users bring the water supply they already have from their dwelling unit. Later in the afternoon (14.00-18.00) there are more activities around the communal toilet when people take their afternoon baths. The users consist of male adults, femaleadults, teenagers and children. After dusk (18.00 until the following morning), there are hardly any activities in the communal toilet. Only few people use the toilet for urinating/excreting, and there are also no clean water collections after the closing of the water storage tank at 18.00 .

The findings suggest that the use of the communal toilet is regulated by informal agreement among the community based on the realisation of needs and availability of resources at different time of the day. This regulating structure of space and time could be considered successful, as there are normally no long queues for the use of the toilets. The acknowledgement on the needs of children and working adults in the morning creates use priority for them in early morning period. Meanwhile, the female adults and the younger children normally use the communal toilet later after the male adults and children have left for work and school. This has created the certain time for domestic chores, primarily washing clothes and bathing the young children. This is also the period of time for other domestic chores like cooking and house cleaning, which also utilise the clean water collected from the storage. The use of the communal toilet in later afternoon period is rather relaxed with nobody needs to hurry for work or school.

Although there are no written rules on who can use the communal toilet at certain period of time, the informal agreement has been emerged naturally within the community, creating a kind of order in the use of the communal toilet. This has demonstrated the collective spatial meaning of neighbourhood (Martin, 2003) and the uniqueness of communal toilet with the community's sense of belonging and control (Burra, Patel \& Kerr, 2003). The structuring on the use of space and time is developed based on the needs of the communities, and the resources available as collective provision.

\subsection{Social structure of owner, maintenance holder and users}

Maintenance is an important issue in the management of communal toilet. This is particularly crucial because of the unique social structure of the neighbourhood with the majority of the residents as tenants, not the owners of the dwelling units. The communal toilet is owned by the owner of the rental dwelling units, butused by anybody regardless of whether they rent the units from him or not, as illustrated in Figure 2. This may raise a question of how the maintenance system should take place, and who should take the roles and responsibilities. In everyday practice, the owner delegates the maintenance responsibility to one of his female tenants occupying a dwelling unit located close to the communal toilet. Her responsibilities include managing the collection of water, filling water into the buckets for collection, storing and collecting the buckets and pulleys ('timba'), collecting money from people and later depositing to the owner, as well as cleaning the toilet cubicles and the surrounding areas. For all these chores she receives a small amount of weekly incentives from the owner. The responsibility on the maintenance of the community toilet has somehow positions her into the role of 'patron' among the residents around the communal toilet. Her active role in everyday management of the communal toilet makes her become a 
centre of contacts among many of the residents, since all clean water transactions always involve interactions with her. Her responsibility is also often extended beyond the maintenance of the toilet; she also takes care of the cleanliness of the areas surrounding the toilets. The informal position that she was assigned to by the owner has put her in the important role in the everyday life of the whole community.

\subsection{Communal toilet as a collective spatial system}

The findings above on the communal toilet in Semper Barat neighbourhood illustrate a complex spatial system practiced by the residents. It becomes clear that the understanding of everyday spatial practice is not a simple one. In fact, a close study of the spatial practice ata micro level would not simplify the understanding of the everyday but rather complicate it (Highmore, 2002). The findings in communal toilet in Semper Barat demonstrates collective spatial strategies involving various actors with different needs and various activities related to communal toilet emerged as basic human needs, and as a community response to their own needs and existing structure.

The clear structure in the pattern of use of the communal toilet, as well as the informal agreement on the use and maintenance of the communal toilet suggests the collective potential within the community in structuring their everyday living. It indicates that the communities have the potential capacity, which is structured by their particular internal strength and weakness (Oldfield, 2000). The collective capacity is triggered by the lack of basic sanitary services in the neighbourhood. The collective action of the community is shaped by their "access to opportunities, poverty or wealth and sociocultural elements" (Oldfield, 2000: 869) that together they determine the spatial practice of the communities towards the place where they live. Unfortunately, such potential of collective action is often underestimated and people tend to depend on the formal intervention from the government rather than optimise their own capacity for actions (Ahmed and Sohail, 2003).

This study has attempted to rediscover the spatial practice underlying behind the physical materiality of the communal toilet - which is physically has insufficient quality. However, the findings of the spatial practice - the facts beneath the surface-has demonstrated how the spatial practice is related to power relations, resistance to authority, domination, and exclusion (Pile, 2001). What happens in a space is definitely a product of the social action and activities, which may also represent how the society responds to the social situation surrounding them. The collective spatial strategies embedded within the community toilet incorporate the ideas of resistance and appropriation which in turns determine the spatiality of the community. The collective actions in structuring the order in the communal toilet demonstrate how the actions by the residents can create a place "as a site of agency and resistance" (Martin, 2003: 371). The collective action found in the communal toilet is primarily aimed at optimising the resources available, whether in the forms of physical resources, social structure and organisation. This is practiced through the space use organization, informal agreement regulating the use pattern and the social structure related to possession, maintenance and use.demonstrate how the actions by the residents can create a place "as a site of agency and resistance" (Martin, 2003: 371). The collective action found in the communal toilet is primarily aimed at optimising the resources available, whether in the forms 
of physical resources, social structure and organisation. This is practiced through the space use organization, informal agreement regulating the use pattern and the social structure related to possession, maintenance and use.

\subsection{Conclusion}

The findings of this study indicate that the communal toilet system becomes a representation of spatial strategies emerged as a result of collective social structure in urban kampung, as well as a collective response to the limited dwelling space provision. The understanding of spatial and social system embedded in the communal toilet system might provide some insights for the development of appropriate spatial strategies for urban kampung communities. Any attempts of intervention for improvement in urban kampung should acknowledge the spatial strategies that are well developed within the community. The most important lesson from this study is that the communal toilet should be considered as a system developed by the community, and it is closely related to other system: neighbourhood space organisation, limited dwelling unit, patterns of activities of residents and social structure of the neighbourhood. By understanding such spatial system, any spatial intervention in urban kampung needs to be developed far beyond the upgrading of physical quality, but should be more grounded on the interdependence among space, inhabitants, and social structure as demonstrated in the communal toilet system. The development of 'standard' communal toilet should incorporate physical quality, social aspects of the community, and the designation of community role and responsibility. In this way, the physical quality is not the sole indicator in determining the quality of services for urban kampung. Similar study would also be needed on other aspects of urban kampung everyday spatial practice. Only by comprehending the spatial practice would it be possible to develop appropriate strategies for improving the quality of life of urban kampung - not merely by introducing an intervention of physical materiality, but also by enhancing the community collective spatial actions and strategies.

\section{Acknowledgement}

The data reported in this paper is part of the research on healthy housing quality funded by Institutional Competitive Grant Programme (PHK-I) Universitas Indonesia, 2010. The authors would like to thank Kristanti Dewi Paramita and Renny Melina as research assistants in the field study in Semper Barat, North Jakarta.

\section{References}

Ahmed, N. and Sohail, M. (2003). Alternative water supply arrangements in peri-urban localities: awami (people's) tanks in Orangi township, Karachi. Environment and Urbanization, 15(2), 33-42.

Borden, I. et al. (Eds.) (2001). The unknown city: Contesting architecture and social space. Cambridge, MA: The MIT Press. 
Burra, S., Patel, S. and Kerr, T. (2003). Community-designed, built and managed toilet blocks in Indian cities. Environment and Urbanization, 15(2), 11-32. Highmore, B. (Ed.) (2002). The everyday life reader. London: Routledge.

Inerfeld, R. B. and Blom, B. B. (2002). A new tool for strengthening urban neighborhoods. Journal of Affordable Housing, 11(2), 128-134

Lefebvre, H. (1991). The production of space. Cambridge: Blackwell.

Martin, D. G. (2003). Enacting neighborhood. Urban Geography, 24(5), 361-85.

Oldfield, S. (2000). The centrality of community Capacity in state low-income housing provision in Cape Town, South Africa. International Journal of Urban and Regional Research, 24(4), 858-72.

Pile, S. (2001). The un(known) city... or, an urban geography of what lies buried below the surface. In I. Borden et al (Eds.), The unknown city: Contesting architecture and social space (pp. 262-78). Cambridge, MA: The MIT Press.

Schnell, I. and Goldhaber, R. (2001). The social structure of Tel-Aviv-Jaffa neighborhoods. Environment and Behavior, 33, 765-95.

Wegelin-Schuringa, M. and Kodo, T. (1997). Tenancy and sanitation provision in informal settlements in Nairobi: revisiting the public latrine option. Environment and Urbanization, 9(2), 181-190.

WHO and UNICEF (2010). Progress on sanitation and drinking water: Update 2010. Switzerland: WHO Press.

Wigglesworth, S. and Till, J. (Eds.) (1998). The everyday and architecture. Architectural Design, Academy Press. 